
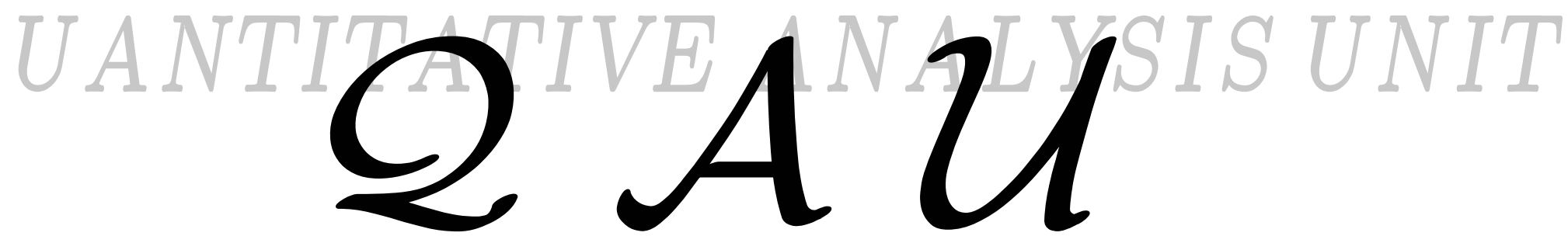

\title{
IS OBESITY CONTAGIOUS? \\ SOCIAL NETWORKS VS. ENVIRONMENTAL FACTORS IN THE OBESITY EPIDEMIC
}

$=$ FEDERAL RESERVE
BANK OF BOSTON

Working Paper No. QAU08-2

Forthcoming in

Journal of Health Economics
Ethan Cohen-Cole

Federal Reserve Bank of Boston

Jason M. Fletcher

Yale University
This paper can be downloaded without charge from:

The Quantitative Analysis Unit of the Federal Reserve Bank of Boston

http://www.bos.frb.org/bankinfo/qau/index.htm

The Social Science Research Network Electronic Paper Collection:

http://ssrn.com/abstract=109832 
Social Networks vs. Environmental Factors in the Obesity Epidemic

\author{
Ethan Cohen-Cole \\ Federal Reserve Bank of Boston \\ Jason M. Fletcher ${ }^{\dagger}$ \\ Yale University
}

\begin{abstract}
This note's aim is to investigate the sensitivity of Christakis and Fowler's claim (NEJM July 26, 2007) that obesity has spread through social networks. It is well known in the economics literature that failure to include contextual effects can lead to spurious inference on "social network effects." We replicate the NEJM results using their specification and a complementary dataset. We find that point estimates of the "social network effect" are reduced and become statistically indistinguishable from zero once standard econometric techniques are implemented. We further note the presence of estimation bias resulting from use of an incorrectly specified dynamic model.
\end{abstract}

Keywords: Obesity, Peer Effects, Social Networks

JEL Classification Codes: D10; D71; I19; J11; Z13

\footnotetext{
- Cohen-Cole: Federal Reserve Bank of Boston; 600 Atlantic Ave., Boston, MA 02210. 617973 3294. 617573 5494 (fax). Fletcher: Yale University, School of Public Health, Divison of Health Policy and Administration; 60 College St., New Haven, CT 06510. 203785 5760. 2037856287 (fax).

${ }^{\dagger}$ Corresponding author.

The authors thank Elizabeth Bradley, Paul Cleary, John Mullahy, David Paltiel, and Jody Sindelar for very helpful comments and Jonathan Morse for research assistance. This research uses data from Add Health, a program project designed by J. Richard Udry, Peter S. Bearman, and Kathleen Mullan Harris, and funded by grant P01-HD31921 from the National Institute of Child Health and Human Development, with cooperative funding from 17 other agencies. Special acknowledgment is due to Ronald R. Rindfuss and Barbara Entwisle for assistance in the original design. Persons interested in obtaining data files from Add Health should contact Add Health, Carolina Population Center, 123 W. Franklin Street, Chapel Hill, NC 27516-2524 (addhealth@unc.edu). The views in this paper are solely those of the authors and do not reflect official positions of the Federal Reserve Bank of Boston or the Federal Reserve System.
} 


\section{Introduction}

The United States has experienced a startling increase in average weight and in obesity over the past few decades (Flegal et al. 2002, Hedley et al. 2004). Though this phenomenon is by now well known and has been widely discussed and debated, there is still little consensus on its causes. One proposed explanation for the increase in obesity is long run technological changes that have impacted food prices as well as the propensity to exercise (Philipson and Posner 2003, Cutler et al. 2003). Though some observers include genetic variation as a potential explanation for the rise of obesity because of the large estimates of heritability of obesity (Stunkard et al. 1990, Coady et al. 2002), most researchers acknowledge that genetic explanations are unlikely to explain the rapid increase in obesity over a relatively short period of time.

One particularly interesting hypothesis recently explored by Nicholas Christakis and James Fowler (henceforth, CF) in the New England Journal of Medicine is that obesity may spread through "social networks effects." 1 In fact, CF report that their findings suggest that social networks indeed facilitate the spread of obesity. ${ }^{2}$ This provocative finding was detailed in many media sources, including the front page of the New York Times. ${ }^{3}$ Media coverage included reports indicating “Obesity is contagious” and “...pick your friends carefully...” (Hellmich 2007) as well as “Add friends to the possible causes of the nation's obesity epidemic" and "...forming ties with underweight or normal weight friends may be beneficial to you" (Dembner 2007). ${ }^{4}$ CF suggest some potential mechanisms by which this may occur, including that having obese peers may change a person's tolerance for being obese or may influence weight-related behaviors such as eating habits, smoking, or exercise. Additional mechanisms suggested by CF include infectious causes of obesity or physiological imitation (see Burke and Heiland, 2007, for an example).

However, as is well known in the economics literature, there are alternative hypotheses that also potentially explain the empirical finding that friends' weight is correlated across time

\footnotetext{
${ }^{1}$ In the language of the Christakis and Fowler article, social network effects are equivalent to endogenous social effects (Manski 1993). We use the terms interchangeably.

${ }^{2}$ They state, “...our observations suggest an important role for a process involving the induction and person-toperson spread of obesity" (p. 377), "The spread of obesity in social networks appears to be a factor in the obesity epidemic" (p.378), and “...obesity appears to spread through social ties” in the summary of their conclusions (p. 370).

${ }^{3}$ See for example, Kolata (2007) for the New York Times, Hellmich (2007) for USA Today, and Dembner (2007) for the Boston Globe.

${ }^{4}$ An official with the National Institute on Aging is quoted in Dembner (2007) as calling the study, "one of the most exciting studies in medical sociology . . . in decades."
} 
that do not require the presence of social network effects. As CF identify in their study, there are at least three reasons why the weight status of individuals could be clustered within reference groups. ${ }^{5}$ The first is that individuals could choose their friends based on factors associated with weight or weight trajectories. In economics, this is typically referred to as selection (CF as homophily). Thus, friendship selection could directly lead to the correlation between friends' weight or weight gain without an individual's weight causally affecting his friend's weight through a social network effect. Second, individuals may adjust behavior because of exposure to common influences. These effects are typically referred to as contextual influences (CF as confounding). For example, the opening of a fast food restaurant, convenience store, gym, etc. near a school could simultaneously affect the weight of all friends in a school's social network. Importantly, the presence of (often unmeasured) shared surroundings can lead to erroneously implicating social network effects in individual outcomes where none exist. ${ }^{6}$ Finally, individuals may alter their behavior as others in their group change theirs. Economists are now generally labeling this an endogenous social effect (CF as social network effects).

We point to three problems with the CF method. First, CF do not include a sufficiently broad set of contextual effects to account for a range of hypothesized causes of the epidemic. Second, the CF method of controlling for selection is much too narrow in scope. Third, the CF dynamic model as estimated produced coefficients with large degrees of bias. (Liu et al. 2006).

Once the first two errors are corrected, evidence for endogenous causes of obesity is thin. We find that the CF results are not robust. In fact, the econometric evidence points strongly to shared environmental factors as the principle operative social mechanism underlying the positive correlation in weight status within reference groups. ${ }^{7}$ We find this remarkable given the preponderance of contexts in which endogenous effects appear present and the fact that this class of empirical models appears to generate the appearance of effects quite easily (Krauth 2006). Our findings point to the difficulty in labeling the source of social effects, particularly in contexts with a direct policy reference. The public health implications given endogenous versus contextual drivers of obesity are quite different.

\footnotetext{
${ }^{5}$ Manski (1993) provided the seminal contribution in economics in describing the alternative mechanisms that can lead to correlated outcomes within reference groups.

${ }^{6}$ See Fletcher (2007) and Lee (2007) on the importance of unobserved group-level characteristics in estimating peer effects.

${ }^{7}$ While many empirical studies label contextual effects as observable group-level phenomena, our main result is to show that the social network effects estimated by CF can be accounted for by unobserved group-level controls. Of course, in Manski's nomenclature, these are also contextual effects.
} 


\section{Data}

We use the Add Health dataset to examine whether there are social network effects in weight outcomes for a national sample of adolescents who transition into early adulthood. ${ }^{8}$ Importantly, we have information on friends for approximately 5,000 individuals, nearly 2,000 of whom are followed over time along with at least one same-sex friend. ${ }^{9}$ This sample size gives us nearly 4,000 person-year observations, slightly larger than the 3,000 used by CF. Summary statistics for our sample are presented in Table $1 .^{10}$

Though there are several important differences between the Add Health and the Framingham Heart Study (FHS) used in CF, the two data sets are sufficiently similar to use to evaluate the role of transmission mechanisms. One important advantage of the Add Health is that it is a national sample of $7-12^{\text {th }}$ graders in 1994/5 instead of being confined to a smaller population with a wider age range. Another advantage is that individuals in our data are in a setting (high school) that is, in principle, more social than the varied lives of individuals in the Framingham study. Finally, by focusing on a national sample of individuals in an active social setting, ${ }^{11}$ we are largely able to rule out that our findings may be due to the nature of our dataset. Thus, while one may believe that the finding of network effects in the FHS suggests an age or social setting difference in effects, it would be particularly difficult to make a generalized claim using the CF results in the absence of similar results from a national sample.

Similarities between the data sets include the time lags between interviews (approximately 3 years on average) and the type of information that was collected (see Table 4A). It will be important for our baseline results to closely mirror those found by CF in order to be able to compare the results from our extended analyses. For brevity and to maximize the overlapping information contained in each dataset, we focus on one of the most interesting and robust results in $\mathrm{CF}$ - the positive relationship between the weight status of individuals and their same-sex friends.

\footnotetext{
${ }^{8} \mathrm{~A}$ full description of the sample design, data, and documentation is available at: http://www.cpc.unc.edu/addhealth.

${ }^{9}$ For individuals for whom more than one friend's BMI information is available, we select the friend with the highest nomination $\left(1^{\text {st }}-5^{\text {th }}\right)$. Nearly two-thirds of the individuals in our sample are only matched to one friend's BMI due to the sample design. We select only one friend to be consistent with CF.

${ }^{10}$ Table 1A in the appendix shows that our analysis sample has similar characteristics as the full Add Health sample.

${ }^{11}$ Studies of peer effects often focus on school and college settings because of the frequent and repeated contact amongst individuals.
} 


\section{Social Network Effects vs. Shared Experience}

Central to our discussion is the distinction between endogenous effects, also labeled "induction" or social network effects by CF, and contextual effects. In the case of obesity, one can think of endogenous effects as describing the propensity to become obese because of the direct interaction with another individual. One may decide to eat more (or higher caloric foods) because their friend, spouse, neighbor does so. Because the two individuals are directly connected, they may influence each other for a variety of reasons. Contextual influences, on the other hand, reflect the shared surroundings of the members of a group that could lead to similar weight outcomes. ${ }^{12}$ Without detailed information on an individual's characteristics, choices, preferences, and environment, it is difficult to discern whether two friends' simultaneous weight gain is attributable to their friendship or to an exposure of a common environmental factor (Manski 1993, Durlauf 2004).

\section{Empirical Methods}

\section{CF Specification and Replication}

CF use data on obesity status for an individual (in their terminology, an "Ego") at a given point in time and estimate its relationship to the obesity status of a friend, spouse or relative (an "Alter") as well as its relationship to the Ego's age, gender, educational level, and past obesity status. The CF specification uses the BMI of an Ego (i) who lives in community (c) at time $(t+1)^{13}$ as a function of the individual's previous BMI, the individual's measured characteristics $(X)$, Alter's $(j)$ current and previous BMI, and an unobserved error term:

$$
B M I_{i c, t+1}^{e g o}=\theta_{1} B M I_{i c, t+1}^{\text {alter }}+\theta_{2} B M I_{j c, t}^{\text {alter }}+\theta_{3} B M I_{i c, t}^{e g o}+\beta X_{i c, t+1}^{\text {ego }}+\varepsilon_{i c, t+1}^{\text {ego }}
$$

This type of model has three features that can, and regularly do, impact inference. First, if unmeasured community-level variables, which we'll denote $c_{c, t+1}$, are positively correlated with individuals’ BMIs, this will bias the estimate of the social network effect. Critically, the absence of a relevant contextual variable can lead to spurious inference on the endogenous variable. CF appear to approach confounding by examining the type and direction of the friendship networks. For example, if individual A declared himself a friend of individual B but not vice-versa, then a

\footnotetext{
${ }^{12}$ Consider the case of two friends: Each friend may simultaneously become obese due to the recent introduction of a high caloric restaurant near his place of residence. Though both soon have a higher BMI, this would not have been attributable to their friendship. The difficulty, of course, is distinguishing between the two potential mechanisms.

${ }^{13}$ Recall that in the Add Health data, there are three waves of surveys for which we have BMI data.
} 
social network effect should appear for A but not B. While network structures can be useful for identification of social network effects, their presence does not rule out the possibility that confounding environmental effects overlap and influence the decisions of network members. ${ }^{14}$ Since CF never directly control for environmental factors, we view their results using directionality of friendship nominations as suggestive rather than conclusive.

Second, similarly incorrect inference can result if an individual's error term $\left(\varepsilon_{i c, t+1}^{e g o}\right)$ is correlated with his friend's BMI. For example, the (unmeasured) propensity to exercise or be involved in sports might increase the chances that two thin individuals are friends. Selection issues appear in this context. CF also provide an ad-hoc solution for this issue. Their claim is that “the use of a lagged independent variable for an Alter's weight status controlled for homophily." Unless selection is conditioned only on this variable, this statement is spurious. As well, in the presence of social interactions, the use of lagged variables can lead to bias in estimation, a topic we turn to now.

Third, the presence of a lagged dependent (or independent) variable in a social interactions model can lead to substantial biases in estimation. Liu et al. (2006) find, using simulation evidence, that a model very similar to (1) above leads to significant bias in estimation relating to the dynamic role of social interactions. ${ }^{15}$ Most importantly for our note is that misspecification of the model or error structure can lead to very large biases and thus incorrect inference. This essentially highlights the well known fact in this literature that inference errors are particularly hard to avoid. Inclusion of a lagged dependent variable appears to magnify the problem. $^{16}$

Acknowledging these concerns, we take the CF model as is and replicate it using the Add Health data. Using equation (1) above, a logistic regression model as proposed by CF, we find the odds that an Ego becomes obese increase by $80 \%$ if his or her Alter is also obese. Broadly,

\footnotetext{
${ }^{14}$ The argument for identification of social network effects using network architecture has been formalized in Bramoulle et al. (2007). The methodology is intriguing and may be sufficient to control for confounding in the CF case, however, CF do not employ it, and it is not clear whether the single-Alter structure of most of their data permit identification in this setup in any case.

${ }^{15}$ The size and direction of bias depends on the type of variable, sample size, panel length and type of misspecification. However, bias appears in essentially every case. That is, correct inference on this type of model requires some type of bias correction.

${ }^{16}$ Of course, simply omitting a lagged dependent variable where it should belong does not alleviate the inference problem!
} 
this is in line with the CF finding of 71\% for same-sex friends. Our basic results are presented in Table 2 as logit coefficients in order to compare with the table in CF.

\section{Extension}

We extend the CF model as follows. Assume the model specification now appears as

$$
B M I_{i c, t+1}^{e g o}=\theta_{1} B M I_{i c, t+1}^{\text {alter }}+\theta_{2} B M I_{j c, t}^{\text {alter }}+\theta_{3} B M I_{i c, t}^{e g o}+\beta X_{i c, t+1}^{e g o}+c_{c, t+1}+\varepsilon_{i c, t+1}^{e g o}
$$

where we have added a set of environmental confounders $\left(c_{c, t+1}\right) .{ }^{17}$ This formalizes the notion of contextual effects. We use either a time-invariant measure as above or a time-dependent set of location-specific (in our case, schools) covariates. Econometrically, this can be expressed as using the following for the environmental confounders: $c_{c, t+1}=t c_{c, t+1}$, where $t$ is a time variable. These represent a much richer set of controls to absorb average changes in social context experienced by all individuals in the sample. To explain further, these school-specific trends account for any environmental factors shared by individuals at the same school. CF control for year effects, but their specification does not capture any shared confounders that also vary across geographic space. For example, CF can control for the fact that the density of fast food restaurants has increased over time but not the fact that the number of fast food restaurants has grown faster in some areas than other areas. For example, suppose that the number of fast food restaurants has grown faster in Boston, Massachusetts than in western Massachusetts. Controlling for year effects (which controls for the growth in the number of fast food restaurants across the states in a given year) is not as appealing as controlling for the number of fast food restaurant in an individual's local area.

Without accounting for the trends, clustering of obesity in social networks that changed over time would incorrectly be absorbed in estimation by the endogenous variable. Though one, in principle, would want many more controls to account for additional contextual effects, we will note shortly that the endogenous effect vanishes even with this relatively simple characterization.

We add to our evaluation by accounting for self-selection of friends (homophily). This is accomplished by looking only at the change in BMI from the time of declaration of friendship until the subsequent weight measurement. Note the distinction between this method and the lagged independent variable used in CF. Our method allows us to distinguish between the desire

\footnotetext{
${ }^{17}$ As mentioned previously, we measure an individual's community by the high school they attend. This equation represents our capture of school-level confounders as a fixed effect.
} 
to become friends based on similarity in weight, which would appear based on the simultaneous measurement of friendship and weight, and the friendship effect of weight gain.

We find that inclusion of a more complete set of controls for school-level environmental confounders leads to a large drop in the coefficient of interest. The odds fall to $50 \%$ in column 3 of Table 2 (logit coefficient reported). As well, Liu et al. (2006) report that an increase in the number of contextual variables reduces bias in most cases.

Since linear specifications more easily accommodate fixed effects and time trends, in Table 3 we estimate models predicting BMI. In our data the association between own-BMI and friend-BMI is 0.05 , which is identical to the CF results. ${ }^{18}$ After controlling for environmental confounding (through school-specific time trends), our estimate falls by over $30 \%$ to 0.037 . Finally, we control for friendship selection by controlling for individual fixed effects. ${ }^{19}$ With this inclusion, the coefficient of interest declines further and becomes statistically indistinguishable from zero. These results, using similar sample sizes and data as CF, suggest that the "social network effects” implicated in CF are not robust to standard economic critiques found in the peer effects literature. In fact, our results suggest that omitted group-level characteristics are the most likely mechanism responsible for correlated body weight within peer groups. ${ }^{20}$

\section{Conclusion}

Our evaluation suggests that the spread of obesity is related to the environment in which individuals live. Though we do not completely rule out the possibility of induction and personto-person spread of obesity, our results suggest that shared environmental factors can cause the appearance of social network effects. While comparing results across datasets that are quite different in design and focus is usually fraught with difficultly, we were encouraged to be able to closely replicate findings of CF using similar methods; this provides suggestive evidence that the structure of obesity decisions is similar across the two samples. It is only when we incorporate

\footnotetext{
${ }^{18}$ OLS results are discussed in the CF article but not presented. The authors provided supplementary material to us upon request.

${ }^{19}$ In a supplemental appendix, we also show that our results here are robust to removing the lagged individual obesity status. Including the lagged individual status is akin to assuming that individuals follow an autoregressive process in obesity. Not only is this very difficult to verify, its incorporation makes inference on the object of interest (friend's influence) very difficult.

${ }^{20}$ The Liu et al. (2006) simulations also find a decrease in estimation error for an increase in the number of contextual effects suggesting that while our extensions may have bias, the finding that the endogenous effects is not significant is robust.
} 
more extensive controls than those found in CF that our results diverge. This divergence in results suggests caution in interpreting correlations in linked individuals’ BMI as social network effects. In fact, we find evidence that community-level factors are able to explain a large share of the "social network effect" in our data.

We find results that suggest difficulty in distinguishing social network effects and environmental confounds of weight gain. And though we advise caution in interpreting the available evidence of a social contagion in weight, we concur with CF on the use of network phenomena, broadly writ, to help to ameliorate the epidemic. Some of the encouraging evidence mentioned in CF, in particular the fact that alcohol and smoking cessation programs are more effective when coupled with peer support, can be exploited independent of the degree of induction present. That is, one need not find evidence that obesity is spread via networks to draw on the logic of peer support to address important issues in public health such as smoking and obesity. ${ }^{21}$ Our data show tightly interconnected networks of friends at the high school level and a high degree of coincidence of obesity within these networks; this can be exploited for interventions even if the cause of the obesity came from a joint external source. Similar arguments can be made to support the notion that obesity can be approached from a public-health perspective rather than a clinical one.

\footnotetext{
${ }^{21}$ In fact, none of the cited articles in CF illustrate a link between success in cessation programs and induction. This is a very interesting question and one that we encourage as a topic of future research. Until that point, the key relationship is simply the presence of a peer group for support — which can and does occur independent of the obesity transfer mechanism.
} 
Table 1

Summary Statistics

Add Health, Analysis Sample

$\mathrm{N}=1,988$; Two Observations Per Person

\begin{tabular}{|c|c|c|c|}
\hline Variable & Wave & Mean & Std Dev \\
\hline $\mathrm{BMI}$ & 2 & 22.66 & 4.38 \\
\hline $\mathrm{BMI}$ & 3 & 26.29 & 5.97 \\
\hline Friend BMI & 2 & 22.50 & 4.10 \\
\hline Friend BMI & 3 & 26.03 & 5.58 \\
\hline Obese & 2 & 0.07 & 0.26 \\
\hline Obese & 3 & 0.21 & 0.41 \\
\hline Friend Obese & 2 & 0.06 & 0.24 \\
\hline Friend Obese & 3 & 0.20 & 0.40 \\
\hline Male & All & 0.44 & 0.50 \\
\hline Age & 2 & 16.24 & 1.51 \\
\hline Age & 3 & 21.70 & 1.50 \\
\hline Black & All & 0.16 & 0.37 \\
\hline Hispanic & All & 0.15 & 0.36 \\
\hline Maternal Education^^ & All & 13.34 & 2.34 \\
\hline Family Income $^{\wedge}$ & All & 49.72 & 46.98 \\
\hline Missing Family Information & All & 0.28 & 0.45 \\
\hline
\end{tabular}

$\wedge$ Imputed Missing Data 
Table 2

Association Between Own-Obesity Status and Friend's Obesity Status

Comparing Results Across Studies and Methods

\begin{tabular}{|l|l|l|l|}
\hline Outcome: Ego Current Obese & & & \\
\hline Logit Specification & CF & Baseline Replication & School Trends \\
\hline & & & \\
\hline Alter Current Obese & $0.62^{\star \star \star}$ & $0.588^{\star \star \star}$ & $0.411^{\star \star}$ \\
\hline & $(0.24)$ & $(0.160)$ & $(0.162)$ \\
\hline & {$[1.71]$} & {$[1.80]$} & {$[1.51]$} \\
\hline Ego Previously Obese & $4.38^{\star \star \star}$ & $4.617^{\star \star \star}$ & $4.634^{\star \star \star}$ \\
\hline & $(0.19)$ & $(0.24)$ & $(0.27)$ \\
\hline
\end{tabular}

Note: ${ }^{* * *} \mathrm{p}<0.01,{ }^{* *} \mathrm{p}<0.05,{ }^{*} \mathrm{p}<0.1$. Robust standard errors in parentheses. Odds ratios in brackets. CF results in Table S1 of web appendix, "Same Sex Friend" Column. We do not include fixed effects in this table as results for short panel logistic specifications are known to be biased.

Table 3

Association Between Own-Body Mass Index and Friend’s Body Mass Index Comparing Results Across Studies and Methods

\begin{tabular}{|l|c|l|l|l|}
\hline Outcome: Ego Current BMI & & & & \\
OLS Specification & CF & $\begin{array}{l}\text { Baseline } \\
\text { Replication }\end{array}$ & School Trends & Trends and FE \\
\hline & & & & \\
\hline Alter Current BMI & $0.05^{\star \star}$ & $0.054^{\star \star}$ & 0.037 & 0.033 \\
\hline $\mathrm{Cl}$ & $(0.02)$ & $(0.023)$ & $(0.023)$ & $(0.039)$ \\
\hline
\end{tabular}

Note: $* * * \mathrm{p}<0.01, * * \mathrm{p}<0.05,{ }^{*} \mathrm{p}<0.1$. Robust standard errors in parentheses. Baseline replication are results that are identical in specification to CF with the exception of data used. School Trends column updates CF specification by adding school-specific time trends. Trends and FE columns includes both school-specific trends and individual level fixed effects. 


\section{References}

Bramoullé Y, Djebbari H, Fortin B. Identification of Peer Effects through Social Networks. University of Laval Working Paper 2007.

Burke M, Heiland F. Social Dynamics of Obesity. Economic Inquiry 2007; 45-3; 571-591

Chou SY, Grossman M, Saffer H. An economic analysis of adult obesity: results from the Behavioral Risk Factor Surveillance System. Journal of Health Economics 2004; 23; 565587.

Christakis N, Fowler J. The Spread of Obesity in a Large Social Network over 32 Years. The New England Journal of Medicine 2007; 357; 370-379.

Coady SA, Jaquish CE, Fabsitz RR, Larson MG, Cupples LA, Myers RH. Genetic Variability of Adult Body Mass Index: A Longitudinal Assessment in Framingham Families. Obesity 2002; $10 ; 675-681$.

Cutler DM, Glaeser EL, Shapiro JM. Why Have Americans Become More Obese?. Journal of Economic Perspectives 2003; 17-3; 93-118.

Dembner A. Obesity Spreads to Friends, Study Concludes. Boston Globe; July 26, 2007. Durlauf SN 2004. Neighborhood effects. In: Henderson JV, Thisse JF (Eds), Handbook of Regional and Urban Economics, ed. 1, vol. 4. Elsevier: Amsterdam; 2004. p. 2173-2242. Flegal KM, Carroll MD, Ogden CL, Johnson CL. Prevalence and trends in obesity among US adults, 1999-2000. Journal of the American Medical Association 2002; 288; 1723-1727. Fletcher JM. Social Interactions and Smoking: An IV/FE Approach. Yale University Working Paper 2007. 
Hedley AA, Ogden CL, Johnson CL, Carroll MD, Curtin LR, Flegal KM. Prevalence of overweight and obesity among US children, adolescents, and adults, 1999-2002. Journal of the American Medical Association 2004; 291; 2847-2850.

Hellmich N. Obesity Can Run in Social Circles. USA Today; July 26, 2007.

Kolata G. Find Yourself Packing It On? Blame Friends. New York Times; July 26, 2007.

Krauth B. Simulation Based Evidence of Peer Effects. Journal of Econometrics 2006; 133; 243271.

Lee LF. Identification and estimation of econometric models with group interactions, contextual factors and fixed effects. Journal of Econometrics 2007; 140; 333-374.

Liu X, Lee LF, Kagel J. Dynamic Discrete Choice Models with Lagged Social Interactions: with an Application to a Signaling Game Experiment. Ohio State 2006; Mimeo.

Manski CF. Identification of endogenous social effects: the reflection problem. Review of Economic Studies 1993; 60-3; 531-542.

Philipson T, Posner R. The Long-Run Growth in Obesity as a Function of Technological Change. Perspectives in Biology and Medicine 2993; 46-3; supplement S87-S107.

Stunkard AJ, Harris JR, Pedersen NL, McClearn GE. The body-mass index of twins who have been reared apart. New England Journal of Medicine 1990; 322 (21): 1483-1487. 


\section{Appendix Tables}

Table 1A

Summary Statistics

Comparison of Full Add Health Sample with Friends Sample

\begin{tabular}{|l|c|rrr|rrr|}
\hline \multicolumn{4}{|c|}{} & \multicolumn{3}{c|}{ Full Sample } & \multicolumn{3}{c|}{ Friends Sample } \\
\hline Variable & Wave & Obs & Mean & Std. & Obs & Mean & Std. \\
\hline BMI & 1 & 20175 & 22.56 & 4.46 & 5220 & 22.63 & 4.46 \\
BMI & 2 & 14352 & 22.95 & 4.71 & 3927 & 23.05 & 4.70 \\
BMI & 3 & 14335 & 26.54 & 6.18 & 3936 & 26.65 & 6.18 \\
Obese & 1 & 20175 & 0.07 & 0.25 & 5220 & 0.08 & 0.26 \\
Obese & 2 & 14352 & 0.08 & 0.27 & 3927 & 0.09 & 0.28 \\
Obese & 3 & 14335 & 0.23 & 0.42 & 3936 & 0.24 & 0.42 \\
Male & All & 20745 & 0.49 & 0.50 & 5303 & 0.48 & 0.50 \\
Age & 1 & 20728 & 17.15 & 1.74 & 5303 & 17.27 & 1.65 \\
Black & All & 20745 & 0.23 & 0.42 & 5303 & 0.18 & 0.38 \\
Hispanic & All & 20745 & 0.17 & 0.38 & 5303 & 0.16 & 0.37 \\
Maternal Education & All & 20777 & 13.16 & 2.25 & 5303 & 13.22 & 2.28 \\
Family Income & All & 20777 & 45.11 & 39.13 & 5303 & 47.11 & 40.37 \\
Missing Family Information & All & 20777 & 0.33 & 0.47 & 5303 & 0.33 & 0.47 \\
\hline
\end{tabular}


Table 2A

Association Between Own-Obesity Status and Friend's Obesity Status Full Results

\begin{tabular}{|c|c|c|}
\hline Outcome: Ego Current BMI & (1) & $(2)$ \\
\hline & Baseline Replication & School Trends \\
\hline \multirow[t]{2}{*}{ Alter Current BMI } & $0.588^{\star \star \star}$ & $0.411^{* *}$ \\
\hline & $(0.160)$ & $(0.162)$ \\
\hline \multirow[t]{2}{*}{ Ego Previous BMI } & $4.617^{\star \star \star}$ & $4.634^{\star \star \star}$ \\
\hline & $(0.241)$ & $(0.265)$ \\
\hline \multirow[t]{2}{*}{ Alter Previous BMI } & $0.465^{\star}$ & $0.611^{* *}$ \\
\hline & $(0.247)$ & $(0.258)$ \\
\hline \multirow[t]{2}{*}{ Wave 3} & $1.101^{* \star \star}$ & $1.533^{\star \star \star}$ \\
\hline & $(0.251)$ & $(0.398)$ \\
\hline \multirow[t]{2}{*}{ Male } & -0.000 & 0.090 \\
\hline & $(0.110)$ & $(0.119)$ \\
\hline \multirow[t]{2}{*}{ Age } & $0.112^{\star \star \star}$ & 0.081 \\
\hline & $(0.036)$ & $(0.051)$ \\
\hline \multirow[t]{2}{*}{ Black } & $0.388^{\star \star}$ & 0.092 \\
\hline & $(0.151)$ & $(0.204)$ \\
\hline \multirow[t]{2}{*}{ Hispanic } & $0.292^{*}$ & 0.261 \\
\hline & $(0.153)$ & $(0.200)$ \\
\hline \multirow[t]{2}{*}{ Maternal Education } & -0.033 & -0.035 \\
\hline & $(0.029)$ & $(0.028)$ \\
\hline \multirow[t]{2}{*}{ Family Income } & -0.004 & -0.003 \\
\hline & $(0.004)$ & $(0.002)$ \\
\hline \multirow[t]{2}{*}{ Missing Family Information } & -0.084 & -0.098 \\
\hline & $(0.123)$ & $(0.131)$ \\
\hline Observations & 3976 & 3616 \\
\hline
\end{tabular}


Table 3A

Association Between Own-Body Mass Index and Friend's Body Mass Index Full Results

\begin{tabular}{|c|c|c|c|}
\hline \multicolumn{4}{|l|}{ Outcome: Ego Current BMI } \\
\hline & Baseline Replication & School Trends & Trends and FE \\
\hline \multirow[t]{2}{*}{ Alter Current BMI } & $0.054^{* *}$ & 0.037 & 0.033 \\
\hline & $(0.023)$ & $(0.023)$ & $(0.039)$ \\
\hline \multirow[t]{2}{*}{ Ego Previous BMI } & $1.006^{\star \star \star}$ & $1.000^{\star \star *}$ & \\
\hline & $(0.014)$ & $(0.014)$ & \\
\hline \multirow[t]{2}{*}{ Alter Previous BMI } & -0.041 & -0.024 & \\
\hline & $(0.027)$ & $(0.028)$ & \\
\hline \multirow[t]{2}{*}{ Wave 3} & $3.230^{\star \star \star}$ & $3.447^{\star \star *}$ & 2.194 \\
\hline & $(0.215)$ & $(0.313)$ & $(1.472)$ \\
\hline \multirow[t]{2}{*}{ Male } & -0.024 & -0.049 & \\
\hline & $(0.087)$ & $(0.095)$ & \\
\hline \multirow[t]{2}{*}{ Age } & -0.043 & -0.055 & -0.074 \\
\hline & $(0.031)$ & $(0.043)$ & $(0.244)$ \\
\hline \multirow[t]{2}{*}{ Black } & 0.089 & -0.099 & \\
\hline & $(0.133)$ & $(0.181)$ & \\
\hline \multirow[t]{2}{*}{ Hispanic } & 0.173 & 0.228 & \\
\hline & $(0.143)$ & $(0.173)$ & \\
\hline \multirow[t]{2}{*}{ Maternal Education } & -0.022 & -0.010 & \\
\hline & $(0.021)$ & $(0.022)$ & \\
\hline \multirow[t]{2}{*}{ Family Income } & $-0.001^{*}$ & -0.001 & \\
\hline & $(0.001)$ & $(0.001)$ & \\
\hline \multirow[t]{2}{*}{ Missing Family Information } & -0.098 & -0.111 & \\
\hline & $(0.099)$ & $(0.105)$ & \\
\hline \multirow[t]{2}{*}{ Constant } & $-5.405^{\star \star \star}$ & -5.460 *** & $15.302^{\star * *}$ \\
\hline & $(0.545)$ & $(0.583)$ & $(1.528)$ \\
\hline Observations & 3976 & 3976 & 3976 \\
\hline R-squared & 0.71 & 0.72 & 0.53 \\
\hline Number of Individuals & & & 1988 \\
\hline
\end{tabular}


Table 4A

Dataset Descriptions

\begin{tabular}{|l|l|l|}
\hline & Add Health & FHS \\
\hline Years of Study & 7 & 32 \\
\hline Average Years Between Waves & 3 & 3 \\
\hline Total Number of Participants & $\sim 20,000^{*}$ & $\sim 12,000$ \\
\hline Analysis Sample (Person-Years) & $\sim 3,500^{* *}$ & $\sim 3,000$ \\
\hline Age Range & $12-27$ & 21 and older \\
\hline BMI measure & Yes & Yes \\
\hline Friendship nominations & Yes & Yes \\
\hline
\end{tabular}

*Although each individual in the original sample of 90,000 students was asked to nominate friends up to five male and five female friends, the study design of the longitudinal component of the data collection was to follow approximately 20,000 randomly selected students from the original sample. Of these 20,000 students, nearly 15,000 listed at least one male or female friend who went to the same school. ${ }^{22} * *$ Individuals in $12^{\text {th }}$ grade in Wave 1 of the data are not followed in Wave 2 due to the original sample design. This results in the loss of nearly 1,000 individuals in our analysis sample.

${ }^{22}$ Nearly 17,500 students listed a male or female friend, but some of these nominations were for students from other (non-sampled) schools or were listed as romantic partners. 